\title{
A IMPORTÂNCIA DO BOM CONVÍVIO ENTRE COMPRADOR E FORNECEDOR NA GESTÃO DE COMPRA E VENDA DO PESCADO EM ARIQUEMES-RO
}

\section{ARTIGO ORIGINAL}

MAGRIN, Naiara Fabiola Souza ${ }^{1}$

GARCIA, Luís Antônio Vieira ${ }^{2}$

MAGRIN, Naiara Fabiola Souza. GARCIA, Luís Antônio Vieira. A importância do bom convívio entre comprador e fornecedor na gestão de compra e venda do pescado em Ariquemes-RO. Revista Científica Multidisciplinar Núcleo do Conhecimento. Ano 05, Ed. 05, Vol. 06, pp. 22-40. Maio de 2020. ISSN: 2448-0959, Link de acesso: https://www.nucleodoconhecimento.com.br/administracao/bomconvivio

\section{RESUMO}

Este trabalho tem como objetivo descrever a importância do bom convívio entre comprador e fornecedor na gestão de compra e venda do pescado em Ariquemes/RO. Tem por objetivo caracterizar essa atividade no município local, apresentando a importância do comprador e fornecedor na comercialização do peixe, bem como, analisando a gestão da compra e venda do produto citado. Destaca-se ainda, a concepção de marketing, que vem crescendo de forma positiva, apresentando hoje um potencial de crescimento e geração de lucro. Com o aumento no consumo do

1 Graduada em Administração de Empresas. Pós Graduada em MBE em Administração Contabilidade e finanças. Pós graduação em MBE em Administração de Empresas.

2 Especialização em andamento em Metodologia do Ensino Superior. Especialização em Citologia Oncótica. Especialização em Pós-Graduação lato sensu - Clínica Transfusional. Graduação em Ciências Biológicas Modalidade Médica. 
peixe, os fornecedores começaram a procurar por técnicas que os mantivessem competitivos no mercado, tendo como prioridade buscar mais informação, tecnologia e desenvolvimento de qualidade da aquicultura. Com a informação disponibilizada tecnologicamente, os clientes estão tornando-se mais exigentes, procurando alimentos saudáveis e frescos. A pesquisa caracteriza-se como bibliográfica de âmbito qualitativo.

Palavras-chave: Comprador e fornecedor, gestão de compra e venda, marketing.

\section{INTRODUÇÃO}

Vista à inevitabilidade de se manterem competitivas no mercado, as organizações devem buscar regularmente a melhoria dos seus processos para serem eficazes nas adaptações e nas novas condições do mercado. Uma maneira de atingir esse objetivo é através de uma gestão de suas redes de fornecimento (SCHMITT, 2004). Desta maneira, o trabalho teve como abordagem a importância do bom convívio entre comprador e fornecedor na gestão de compra e venda do pescado em AriquemesRO.

O bem estar do cliente torna-se indispensável para o sucesso dos negócios e o bom convívio entre comprador e fornecedor.

Utilizando de estratégias de marketing, os produtores de peixes começaram a focar no mercado consumidor, tendo como objetivo aumentar o número de clientes. Os consumidores vêm exigindo cada vez mais dos valores e qualidade dos produtos e com isso, busca mais informação para a tomada da decisão de compra (SCHMITT, 2004).

Devido ao aumento do consumo do pescado, a competitividade aumentou e os gestores começaram a entender e melhorar o relacionamento com seus abastecedores, melhorando a administração no processo de compra e venda do peixe na região de Ariquemes-RO. 
Como objetivos articuladores deste artigo, estão os princípios de identificar o sistema do trabalho através da definição do tipo de pesquisa, assim como das definições das etapas, métodos e instrumentos empregados no alcance dos objetivos apresentados. O trabalho estabelece, é encerrado com um cronograma que pretende organizar a dissertação.

O trabalho é estruturado em 4 (quatro) capítulos. O primeiro trata da abordagem sobre o tema, dando relevância à importância do bom convívio entre comprador e fornecedor na gestão de compra e venda do pescado em Ariquemes/RO, pois, o fornecedor, por consequência, passa a ter responsabilidade por uma parcela de satisfação do cliente envolvido na compra do produto ou serviço. Tendo em vista a importância da gestão de compra e venda para competitividade do mercado atual.

O referencial teórico do capítulo 2 aborda a tarefa do marketing e sua dimensão em elaborar, viabilizar e fornecer bens e serviços aos clientes. Da mesma maneira, orientando o bem estar e satisfazendo os desejos dos clientes locais, e a partir desse entendimento, oferecendo produtos e serviços com o intuito de gerar mais renda às empresas, fazendo dos consumidores, clientes satisfeitos. Isso tudo é viabilizado através da amostragem do plano estratégico do projeto.

No capítulo 3, é explorada a metodologia, que fornece o método utilizado da pesquisa, processo de elaboração tendo como objeto de estudo a análise descritiva. A pesquisa é de natureza bibliográfica com enfoque qualitativo e coleta de dados. O âmbito desta pesquisa está ligado ao relacionamento do fornecedor e comprador, administração de compras e venda, a importância do peixe na alimentação, comercialização do pescado e Marketing.

No quarto capítulo coloca-se em prática a importância do relacionamento entre comprador e fornecedor do pescado, mostrando que, desenvolvido corretamente, esse relacionamento torna-se uma atividade aliada à sustentabilidade, já que substitui a pesca extrativista, ajudando com a proteção do meio ambiente e criando um ponto positivo para a aquicultura local. 
Finaliza-se a discussão apresentando as conclusões mais relevantes diante dos desfechos deste trabalho, listando também os assuntos que não foram abordados, mas que são considerados importantes para indagações futuras.

\section{A IMPORTÂNCIA DO COMPRADOR E FORNECEDOR}

Para que a transação comercial entre comprador e fornecedor se torne harmoniosa, é necessário que a colaboração entre empresas e fornecedor seja cultivada, promovendo uma convivência duradoura e promissora, facilitando o relacionamento e trazendo governança (Ford te AP, 2003).

No estudo foram analisados quatros fatores importantes para obter esse objetivo, são eles: a confiança, a inovação, o foco no cliente e a satisfação. Uma das relações mais utilizadas na comercialização de produto ou serviço é a confiança. Para que haja essa harmonia entre o processo de compra e fornecimento é necessário que exista a confiabilidade em vários aspectos (FRIMAN et al.,2002).

Confiança é o ato de confiar. Para Ford. et al (2002), confiar é crer na capacidade de cumprir as promessas e os deveres contratuais. O cumprimento desses deveres estabelece confiança entre as partes e colabora para o melhor desempenho.

A confiança e a troca entre parceiros mostra uma característica de convívio inovador. Para Lee et al. (2001), a inovação vem se tornando uma ferramenta valiosa para aqueles que buscam se tornar competitivos no mercado. A qualificação e diferenciação no produto ou serviço possibilitam que o fornecedor obtenha destaque no mercado competitivo.

As empresas que inovam obtêm vantagem em relação as demais, podendo alcançar novos conhecimentos, novos mercados, aumentar seu lucro e agregar valor aos seus produtos. Assim, o investimento na inovação vem fidelizando clientes e criando uma imagem positiva, trazendo ainda vantagens na venda que retornam em lucros para as empresas segundo Drucker (1985). 
A inovação é, mais do que nunca, um diferencial competitivo para as empresas que buscam mudanças e oportunidades de êxito. Os clientes são a razão da organização, para que as empresas tenham a existência no mercado, elas precisam focar no cliente (DRUCKER, 1985).

Com o acesso às informações comerciais, os clientes estão mais exigentes, com isso não basta ter apenas foco no cliente, é preciso saber analisar o cliente (MCKENNA,2002).

A satisfação do cliente vem sento um conceito bem semelhante ao de qualidade. Pois, quando um produto ou serviço preenche a necessidade do cliente, este fica sempre satisfeito. As semelhanças estabelecem-se, uma vez que ambas estão intimamente relacionadas e dependentes da percepção do cliente (PHILIP KOTLER, 2007).

Segundo Slongo (2004), satisfação dos clientes é a relação dos serviços prestados pela empresa, é a consequência da credibilidade e da confiabilidade. Já a insatisfação é a falta de comunicação e a demora da informatividade.

[...] Um cliente tem vários níveis de satisfação. Se o produto atingir a expectativa, ele ficara satisfeito. Se a expectativa for abaixo do desempenho desejado ele ficará insatisfeito. O produto tem que exceder essas expectativas, para que o cliente fique satisfeito ou encantado (SCHMITT, 2004, p. 23).

Para que haja a satisfação nos negócios, os clientes esperam a reciprocidade de compromisso entre compradores e fornecedores.

\subsection{RELACIONAMENTO ENTRE COMPRADOR E FORNECEDOR}

Para Claro (2004), a confiança e as informações são primordiais no relacionamento entre compradores e fornecedores. Assim também, segundo Ford et al. (2003), as alianças estratégicas entre compradores e fornecedores estão cada vez mais comuns e isso se dá através da obtenção de vantagens competitivas. 
A confiança é ressaltada como sendo a mais importante no desenvolvimento da cooperação (ANDERSON, 1990).

Para Heide, John (1992), A mudança de transação de mercado e a ação conjunta de planejamento e resultado de definição de metas envolvendo comprador e fornecedor, influencia positivamente em seus acordos. É importante ressaltar que a confiança e a credibilidade para ambas as partes diminuem a obrigação e deveres que são normalmente encontradas em contratos.

O crescimento de uma organização depende da consolidação e relacionamento na resolução de um problema. Sendo importante a procura por saber a causa e sua solução em algumas falhas técnicas ou situação indesejada (LUSCH; BROWN, 1996).

As empresas que apresentam ações conjuntas podem produzir melhores resultados que as empresas que optam por serem isoladas (ANDERSON; NARUS, 1990).

A confiabilidade no relacionamento entre comprador e fornecedor é significativa para troca de informações, pois pode ser considerada como base relacional para o decorrer das ações conjuntas (ZAND, 1972).

Quanto maior a segurança de um comprador em seu fornecedor, mais eficazes são as ações conjuntas com os fornecedores. As empresas que buscam crescer junto com seus colaboradores, tendem a atingir seus objetivos (CLARO, 2004).

A confiança deve ser conquistada por comunicação, trocas de ideias e informações sobre o objetivo entre ambos, as organizações estão desenvolvendo líderes, gestores, empresários e colaboradores com a função de conquistar clientes. As organizações também incentivam os relacionamentos colaborativos com fornecedores com o objetivo de incentivar as empresas a contribuir mais com os fornecedores.

Pesquisas apontam que relacionamentos com fornecedores têm um significado muito maior do que boa compra, além de entregar produtos nos prazos certos e com preços acessíveis, também podem realizar muito mais, realimentando a confiança neles 
depositados, investindo em ativos e respondendo as ações conjuntas dos compradores (CLARO, 2004).

\subsection{GESTÕES DE COMPRA E VENDA}

A gestão de compras é de extrema importância para relação do comércio. Segundo Francischini, Gurgel (2002) a centralização da compra traz um aspecto positivo em relação aos preços médios de aquisição, mas dependendo do tipo de compras, é aconselhável que as aquisições sejam descentralizadas.

A gestão de vendas analisa os clientes, priorizando o atendimento, tanto no prévendas, como no pós-vendas. O gestor tem de estar sempre atualizando com os dados sobre as vendas dos insumos, sabendo a quantia e quando são utilizados ou vendidos, a fim de tornar satisfatório o produto ou serviço oferecido.

Em análise de mercado, a função das compras passou a ser indispensável para gestão de recurso material de uma empresa. Toda empresa deve estar atenta à compra, procurando sempre satisfazer sua necessidade, priorizando atender a necessidade do período (DIAS, 1993).

O setor de compras está relacionado com o nível de estoque. A ele competiu o equilíbrio na quantia de insumo a ser comprado, tendo como objetivo reduzir custo e melhorar os lucros. Assim, a função importante da gestão de compras é cuidar para que a empresa tenha sempre um nível de estoque equilibrado. Segundo Pozo (2010), a elevação de custos pode acarretar atrasos de produção, prazos, desempenho e preços, causando consequência e insatisfação ao cliente.

Segundo Dias (1993), para atingir uma quantidade de vendas e um perfil competitivo, seguida de lucros satisfatórios, deve-se sempre buscar custos, podendo concluir que os objetivos básicos são. a) Ter um fluência contínua de suprimento para que a produção seja atendida; b) Organizar o fluxo que seja aplicado um pouco de investimento que afete o sistema operacional da produção; c) Comprar insumos com preços baixos, visando a qualidade e quantidade determinados e d) Procurar em uma 
negociação justa às melhores condições para empresa, especialmente em condições de pagamento.

Um dos requisitos mais importantes para organização é planejar, supervisionar os estoques, desde a matéria-prima, até a entrega ao cliente do produto finalizado. Antigamente, a grande maioria das empresas bloqueava o controle de material como secundário e, quando algumas delas paravam de funcionar por falta de estoque, davam-se conta da importância de planejar e controlar o fluxo de materiais de maneira certa. Planejar o estoque exige observação em cada nível de planejamento, por esse motivo, está integrado no planejamento de produção.

A gestão de estoque visa à melhora da qualidade dos produtos e aumento do controle de custos da empresa. Definindo a qualidade de estoque de cada produto, onde só é capaz de ter-se uma definição a partir da demanda de consumo do produto.

\subsection{COMPRAS/VENDAS: FUNÇÕES E IMPORTÂNCIA}

A função de compras é responsável pela movimentação de materiais na empresa, pelo acompanhamento junto ao fornecedor e pelo compromisso da entrega. Os prazos de entrega são de suma importância para o departamento de criação e vendas, a atribuição nas compras pode ajudar nos problemas em ambas as áreas e fornecer mais lucratividade para as empresas.

Os gestores de compras fazem uma ligação importante entre a empresa e seus abastecedores. O serviço de compras de uma empresa executa a função e responsabilidade de estabelecer o fluxo dos materiais junto ao fornecedor, com a importância de fortalecer e manter boas relações com os fornecedores e expandir com futuros fornecedores (CHIAVENATO, 2005).

Segundo Chiavenato (2005), o setor de compras tem a finalidade de compra de insumos, elementos e serviços a fim de suprir as necessidades da empresa, bem como o acesso direto à informação vinda da alta gerência para que possa atuar de forma estratégica. A falta de comunicação direta pode impedir que as informações 
sobre o mercado sejam trabalhadas pelo órgão de compras, que contribui diretamente com a ligação entre empresa e seu ambiente externo.

O setor de compra é considerado um fator de lucro e não somente de custo, pois, quando bem administrado, ele traz benefícios econômicos, lucros para a organização e vantagens competitivas. Toda empresa bem administrada produz, vende e compra melhor. O setor de compras desenvolve e mantém fontes de abastecimento adequadas para atingir seu objetivo. $O$ órgão de compras não apenas importante para manter a necessidades de insumos e materiais da empresa, como também garante a qualidade assegurada, economia, prazos e, por fim, a lucratividade (CHIAVENATO, 2005).

O setor de compra precisa das informações de cada ramo e necessidades de materiais. Empresas, indústrias, grandes lojas, supermercados e empresas de serviços organizam suas compras conforme os materiais a serem comprados, as exigências do processo produtivo, as características do mercado fornecedor e outros fatores preponderantes (CHIAVENATO, 2005).

Para a organização, compras é o conhecimento entre fornecedor e a empresa. Contudo, a procura por novos provisores para que os insumos estejam organizados de acordo com o tempo certo, permite concluir que a função da compra tem um papel estratégico e de imensa relevância para as empresas.

A atividade de compras envolve uma série de etapas que, impreterivelmente, devem ser cumpridas, cada uma no seu tempo, pois, a fase é acionada cada vez que haja a necessidade de adquirir algum material. Pois a reposição desses materiais ocorre repetitivamente, isso porque o processo pode ser aperfeiçoado com objetivo da eficiência cada vez maior (CHIAVENATO, 2005).

A cadeia de suprimentos está relacionada a bens ou produtos que uma organização mantém para atender a uma determinada demanda futura. A importância do suprimento se estende a todas as empresas, independentemente do ramo de negócio toda empresa terá de constituir 
estoques, mesmo que seja para materiais de uso e consumo (SLACK, 2002. p. 415).

Com o funcionamento correto da gestão de compras, as contratações entre fornecedores são asseguradas. Assim podendo obter um menor custo possível com a qualidade superior. O propósito da gestão de compras torna-se imprescindível por diversos fatores, dentre os quais o valor investido, a necessidade de dimensionar os estoques adequados, garantir qualidade, evitar estoque em excesso e faltas, garantir a integridade dos materiais. A área de compras não é um fim em si próprio, mas uma atividade de apoio fundamental ao processo produtivo, suprindo as necessidades de materiais (POZO, 210, p.133). "Portanto, o investimento correto na gestão de compras minimizando as necessidades de capital investido" (DIAS, 1993).

Dentro da visão de vendas, é importante identificar que a comunicação entre vendedor e cliente é muito importante, pois a tendência é que o vendedor deixe de ser somente vendedor e passe a ser o comunicador e amplificador dos negócios, aquele que compreende e pensa no processo de negociação, visualiza a empresa, o cenário opositor, debate sobre a oferta e procura, pensa sobre o estratagema, acredita no que vende e entende o que está vendendo passa credibilidade e segurança ao cliente (LAS CASAS, 2005). Para Kotler (2000), os vendedores são a representação da empresa perante o cliente, com isso é interessante que a empresa invista em alguns pontos de desenvolvimento de força de vendas. A definição de especialização representa uma decisão estratégica por meio da qual é possível obter proveito e diferenciar o risco da empresa. Assim sendo, a estratégia na área de vendas é essencial na força das vendas e deve ser capacitada e qualificada para ter demandas de mercado onde se visa que cada cliente é único, especial e cada dia mais exigente, além de estar em incessante evolução.

Segundo Castro Neves (2008), vendas é a previsão de demanda onde se avalia a escolha dos vendedores contratados, definição de territórios, especialização por tipo de cliente, entre outras decisões que são informações importantes a serem consideradas. 
O vendedor está diariamente em contato com o mercado, assim ele pode perceber a ação a ser tomada e os preços da concorrência, os resultados das promoções e propagandas que a empresa desenvolve, as falhas e desejos dos clientes não correspondidos, assim opinando dentro da organização de vendas, sobre novas atitudes e estratégias a serem tomadas (LAS CASAS, 2005).

Ainda, segundo Las Casas (2005), a estrutura da administração de vendas é focar no cliente e perceber quais são suas necessidades, o que a empresa pode fazer para atendê-lo da forma que espera, tanto no pré-venda quanto no pós-venda, tornando assim um cliente fiel e satisfeito com a empresa. Além de que, a organização contribui para a manutenção de uma relação harmoniosa entre os departamentos, ajudando na colaboração e interação através da série de informações entre ambos.

Para se obter sucesso da gestão de vendas e recrutamento, é necessária a seleção, treinamento, supervisão, pagamento e motivação à medida que as tarefas se aplicam à administração de vendas.

Selecionar vendedores seria simples se já estive por conhecimento os gostos de cada cliente. Um bom começo é perguntar aos clientes que características eles preferem em vendedores. Muitos dizem que querem que o vendedor seja honesto e confiável, que conheça o produto e as atividades do setor e que seja prestativo. A empresa deverá procurar vendedores hábito as essas seleções (KOTLER, 2000).

Segundo Kotler (2000), os vendedores servem como uma espécie de elo pessoal entre os consumidores e a empresa. $O$ vendedor representa a empresa para muitos dos seus clientes, pois é ele quem leva as mais importantes informações sobre o cliente à empresa. Para ser um bom vendedor deve-se primeiro conhecer seu produto e conhecer seus compradores, é interessante que a empresa tenha táticas de vendas e pessoas capacitadas para negociarem, pois além de venderem o produto, o vendedor estará representando e passará a imagem da empresa a seus clientes. $\mathrm{Na}$ maioria das vezes, o vendedor é a única ponte que liga o cliente à empresa (KOTLER, 2000). 
Dominar essas habilidades não é o suficiente. Para Kotler (2000), os profissionais de vendas têm por obrigação saber analisar dados de vendas, saber medir o potencial do mercado em questão, desenvolver estratégias e principalmente planos de marketing, desenvolver ainda suas habilidades de análise de mercado, pois as empresas acreditam que as forças de vendas se tornam mais eficaz a longo prazo por compreenderem tanto de vendas quanto de marketing, sendo esse o diferencial de uma empresa em potencial.

Segundo Las Casas (2004), algumas das estratégias de vendas estão na capacitação de seus vendedores, buscando objetivar maior retorno desse investimento feito na contratação o mais imediato possível. Os treinamentos em vendas são feitos com relação a características de produção dos clientes, da empresa, do mercado e sobre métodos de vendas (CASTRO; NEVES, 2008).

A visão tradicional que norteia a gestão de venda deve ser dentro da realidade e características dos mercados-alvo em que atuam e na posição almejada. A grande parte das organizações têm a preocupação com o volume de vendas gerado, cabendo ao departamento de marketing à tarefa de apurar a estratagema e rentabilidade (KOTLER, 2000).

\subsection{MARKETING}

Marketing e a diversificação dos produtos no mercado consumidor: por esse motivo o consumidor tem várias opções de escolha na compra do produto ou serviço. Além disso, quando o fornecedor diferencia seu produto da concorrência, ganha vantagem competitiva. Isso se dá através da diversificação dos produtos oferecendo e influenciando o consumidor para o consumo.

Marketing é um benefício em forma de satisfação para o cliente. Tendo como atividades, as que orientam os fluxos de bens e serviços do local onde são gerados até os consumidores finais, para Kotler (2000) é um processo social onde os consumidores conseguem aquilo que precisam e desejam com a criação, oferta e livre negociação de produtos ou serviços. 
A análise da colocação é indispensável para avaliar a Importância da imagem da empresa. A conduta de projetar a mercadoria e a imagem da organização com a intenção de se posicionar de uma forma diferenciada na escolha do grupo-alvo.

É fundamental para o marketing, o desenvolvimento estratégico de uma organização, para definir a opinião do mercado sobre a empresa, saber diferenciá-la dos concorrentes e desenvolver um mercado bem definido (KOTLER, 2000).

Para Peter Donnelly Jr. (2013), a concepção de marketing é administrar os gestores para verificar a necessidades dos clientes, logo, os produtos e serviços que satisfaçam as necessidades do consumidor. Com isso, as empresas devem focar na criação de relacionamento de longo prazo com o cliente, gerando satisfação do cliente e, consequentemente, maior lucro para a empresa.

As principais funções de marketing: a) a gerência do produto, onde é feito o processo de acompanhamento desde as pesquisas iniciais, design, fabricação, até chegar aos mercados; b) a definição do preço, sua estratégia é definir a autossuficiência de um determinado produto, a fim de considerar seus rendimentos de lucros à empresa, no entanto, não pode ser tão alto que desestimule a venda e nem tão baixo que deprecie o produto, fazendo o cliente acreditar que tem algo de errado nele, geralmente é feita uma análise dos produtos concorrentes, onde se paga o preço e recebe o benefício dele; c) a distribuição depende da forma como é feita a venda, normalmente são o atacado, o varejo e as vendas de manufatura; d) a publicidade, essa é uma das principais técnicas do marketing, onde se cria e desenvolve, ou até mesmo muda, os hábitos do consumidor, fazendo com que ele tenha uma visão diferenciada e positiva de determinado produto com o concorrente; e) vendas, é o contato direto entre o comprador e o vendedor, este deve usar técnicas que envolvam o cliente de tal forma que ele comece a dar preferência a essa empresa e não à concorrente, tornando uma imagem positiva da empresa e do produto oferecido (KOTLER, 1994).

Para Kotler; Armstrong (2004) marketing é importante para o sucesso da organização, independente do seu porte, com ou sem fins lucrativos. O Marketing vai além do que está exposto aos olhos, está em jornais, revistas, meios de comunicação, oferta em 
internet e campanhas diversas, por trás do marketing há sempre uma rede de pessoas e atividades que competem pela sua atenção e seu dinheiro.

Atualmente a comercialização é entendida como o bem estar e necessidades, desejos dos clientes e não mais como um efetivado de faturação. Se o profissional de marketing entender as necessidades dos consumidores, desenvolverá um produto que corresponde às expectativas do cliente e agrada facilmente o consumidor na questão de valor agregado e bom preço (KOTLER; ARMSTRONG, 2004).

Inicialmente, o marketing estava mais relacionado com a transferência de bens e serviços. Posteriormente, o conceito de marketing relativo à satisfação dos desejos e das necessidades dos consumidores passou a ser ampliado e aplicado também em outras áreas como política, turismo [...] (LAS CASAS, 2006, p. 9).

O Marketing desempenha a função de atender as necessidades do cliente, isso é avaliado de fora pra dentro, com finalidade de deixar o cliente sempre satisfeito. $\mathrm{O}$ relacionamento entre empresas e clientes passa a ser importante para o sucesso da organização, pois é ela que trabalha nas estratégias que estarão focadas nas necessidades e satisfação dos clientes, sempre conquistando e cuidando dos mesmos (KOTLER, 2000, p.41).

\section{METODOLOGIA}

A elaboração desta pesquisa é de natureza bibliográfica com enfoque qualitativo, tendo como objeto de estudo a análise descritiva da importância do bom convívio entre compradores e fornecedores na gestão de compra e venda do pescado no município de Ariquemes/RO. O âmbito desta pesquisa está ligado à forma com que é efetuada a compra e a venda do peixe em torno do município local.

\subsection{PLANEJAMENTO E ETAPAS DA PESQUISA}

Esta pesquisa foi conduzida conforme as etapas ilustradas no quadro abaixo: 
Quadro 01 - Etapas da pesquisa

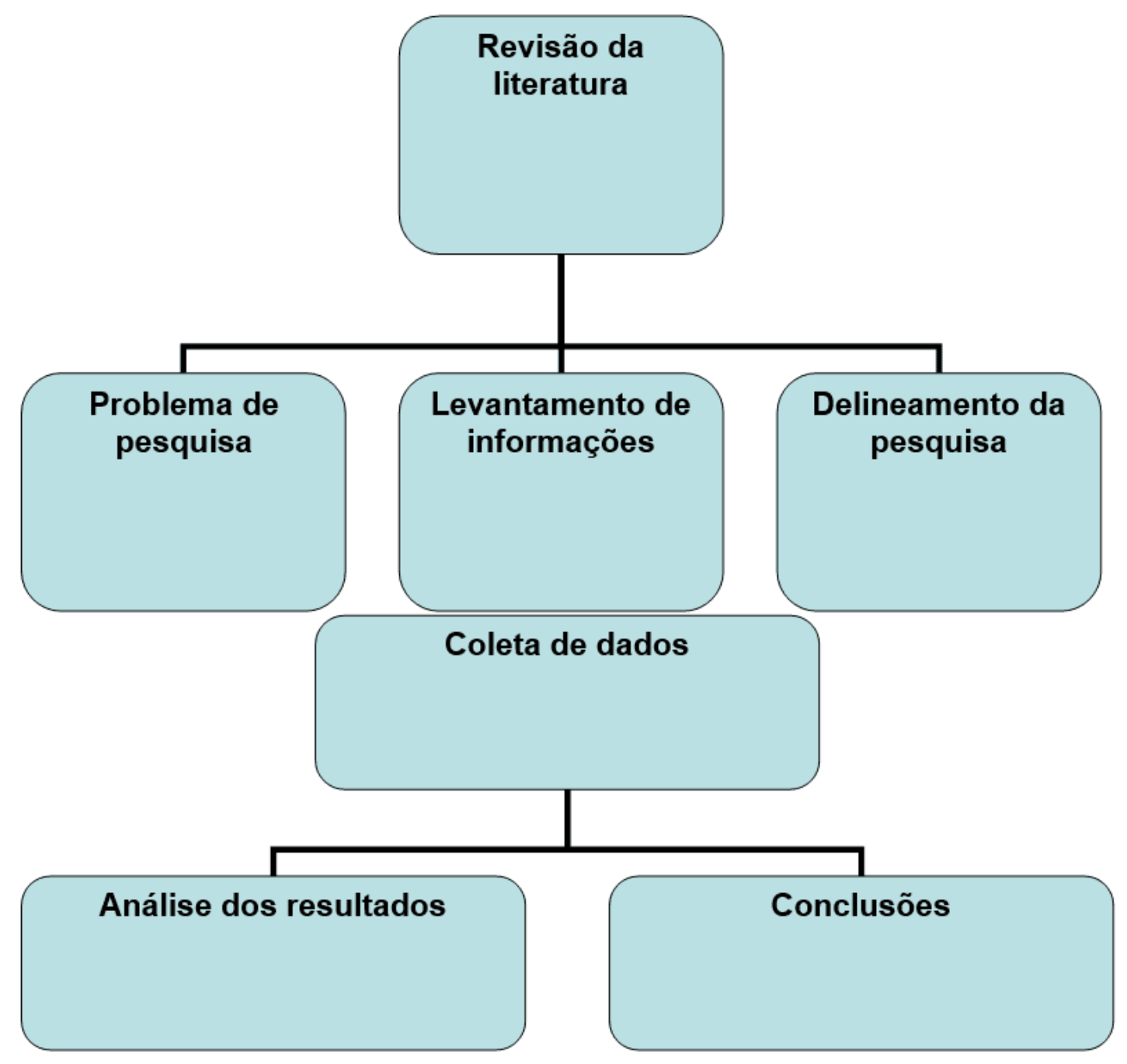

Fonte: Autor, 2019.

As etapas da pesquisa, conforme ilustra o quadro acima foram acontecendo conforme o desenvolvimento do trabalho em si. Em primeira mão houve a revisão da literatura disponível para determinar-se qual seria o foco do estudo em questão, neste caso, o problema de pesquisa. Em seguida foram feitos os levantamentos de informações juntamente com o plano da pesquisa.

Com todos esses dados em mãos, a partir de uma diversidade de literaturas pesquisadas, houve a coleta e tabulação dos referidos dados, e através das análises dos resultados chegaram-se as conclusões finais. 


\subsection{ANÁLISE E DISCUSSÕES}

A busca por uma vida mais saudável tem mudado os hábitos alimentares cada vez mais na rotina da população. O interesse por alimentos que engloba uma maior qualidade de vida vem aumentando e isso se reflete também no mercado consumidor.

A eficácia do peixe para prevenção de doenças fez com que ele se tornasse um alimento importante na mesa do consumidor. Seus nutrientes, proteínas e vitaminas são de enorme poder para a saúde humana. O consumo do peixe é muito importante, principalmente na infância, pois, previne uma grande variedade de doenças, além de conter nutrientes que ajudam na fase de crescimento da criança.

O setor de pescado está em amplo avanço, pois a carne do peixe é um alimento saudável e de fácil preparo, podendo ser preparado de diferentes maneiras e combinações de ingredientes que complementam seu aproveitamento nutritivo.

A compra do peixe fresco vem se destacando, e tendo um recebimento favorável no mercado quando ele está na sua forma in natura, ao contrário da grande maioria dos outros produtos alimentares que exigem conservantes, corantes e que prejudicam a saúde humana.

A piscicultura é uma das áreas da aquicultura em que o objetivo é a criação de peixes, podendo ser para venda ou para consumo próprio. A criação de peixes tem que ser gerenciada com técnicas e manuseios corretos para facilitar as vendas e consumo, os sistemas mais utilizados são de viveiros e em tanques com redes. Conforme as técnicas aplicadas pelo piscicultor, à criação de peixes pode apresentar grande interesse sócio econômico, em função da sua rentabilidade.

A piscicultura vem crescendo muito no Brasil devido ao seu rápido retorno ao capital investido. O ramo da piscicultura deve ser estudado antes de ser explorado, pois a falta de noção de como criar o peixe pode trazer despesas desnecessárias. O piscicultor deve ter conhecimento para ter um bom lucro e obter um produto de qualidade. 
Segundo Ostrensky Boeger (1998), a piscicultura tem todo um processo para o seu cultivo. O produtor precisa saber colocar ração de forma adequada, deve-se ter conhecimento de técnicas de criação corretas para os peixes no tanque, controlar o $\mathrm{PH}$ da água, os produtos químicos, assistência técnica e fazer um estudo de mercado para que assim, os compradores tenham um produto de qualidade adquirido. No Brasil a piscicultura é desenvolvida principalmente por pequenos produtores, que consideram essa atividade como uma forma de completar a renda da família (OSTRENSKY; BOEGER, 1998). Ao iniciar o cultivo de peixes o produtor deve saber qual a espécie exigida pelo mercado, pois será este o produto a ser vendido. Outro aspecto também interessante antes de iniciar a piscicultura é saber o quanto irá investir e o quanto pretende produzir em sua propriedade (OSTRENSKY BOEGER,1998).

A piscicultura é uma atividade que envolve desde a escolha da espécie até o local e valor da venda. O Município de Ariquemes vem tendo uma ótima fonte de renda com a criação de pesca comercial. O pescado vem se tornando um atrativo econômico para os produtores rurais, especialmente aos da agricultura familiar devido à criação não depender de grandes áreas territoriais.

A compra do peixe pode acontecer de várias formas, aquela em que o fornecedor procura o comprador para informar que possui o produto já em condições de venda pronta para a despesca, outra forma é aquela em que o comprador vai até o produtor em busca do pescado com a intenção de saber se o produto já está no ponto de venda, ou seja, se o produto seguirá os quesitos necessários que satisfazer as exigências do consumidor final.

É fundamental para organização entender seu consumidor e desenvolver técnicas que priorizem os clientes na organização, já que é ele o fundamento para o crescimento e desenvolvimento do empreendimento.

Os consumidores estão cada vez mais atentos em relação ao preço em sua busca por valor e também a forma de compra casada, onde o comprador possui os maquinários adequados para a confecção dos tanques de peixes e este receberá seus 
serviços de hora máquina a longo prazo, tendo como pagamento o próprio peixe criado pelo vendedor.

A transação de venda do peixe segue um rito de confiança, já que tudo é combinado com antecedência, o representante de compra que analisará se o produto está realmente no ponto de venda, sendo feita uma coleta aleatória, por amostragem, onde serão observados todos os quesitos necessários. No fator quantidade é valorizada a confiança na palavra dada pelo vendedor para se programar a despesca com dia e hora certa.

Para que o pescado seja de qualidade ele deve ser retirado da represa com algumas técnicas, como não dar ração no dia da despesca, pois pode prejudicar a estrutura do produto até sua chegada ao consumidor final, deverá abaixar a água da represa para facilitar o manejo da pesca. Todo esse procedimento é feito após o combinado, onde a reciprocidade da confiança está em primeiro lugar.

\section{CONSIDERAÇÕES FINAIS}

A necessidade de entender que as preferências do consumidor jamais terminam a partir de um único estudo, sobretudo quando se trata de um assunto pouco falado, como a compra e venda do pescado e seus benefícios à saúde humana. O consumo de carne de peixe se mostrou importante na dieta e na economia do município de Ariquemes/RO.

Com o conhecimento teórico e prático, o produtor de peixe vem se destacando e mostrando mais qualidade no seu produto, tendo como funcionamento o aumento de venda no mercado local. Com esse conhecimento, o produtor vem trabalhando com tecnologias e combinações que ampliam corretamente sua forma de administrar as imensas cargas de trabalho e de dedicação no seu dia-a-dia.

Conclui-se que pondo em prática os fatores de relacionamento entre compradores e fornecedores do pescado, surgem muitas oportunidades para quem pretende trabalhar com essa cadeia de produção, com essa vantagem o consumidor se 
beneficia e a pesca extrativa diminui, contribuindo com a preservação do meio ambiente e tornando-se um ponto positivo a favor do marketing da piscicultura local.

\section{REFERÊNCIAS}

ANDERSON, E.; WEITZ, B. Determinants of continuity in conventional industrial channel dyads. Market Science, v. 8, n. 4, p. 310-323, 1989.

ANDERSON, J. C.; NARUS, J. A. A model of distributor firm and manufacturer firm working partnerships. Journal of Marketing, v. 54, n. 1, p. 42-58, 1990.

CASTRO, Luciano Thomé; NEVES, Marcos Fava. Administração de Vendas Planejamento, Estratégia e Gestão. Editora Atlas. São Paulo, 2008.

CHIAVENATO, Idalberto. Administração de Materiais: Uma abordagem Introdutória, Rio de Janeiro: Elsevier Editora Ltda, 2005.

CLARO, Danny Pimentel; CLARO, Priscila Borin de Oliveira. Artigo - Gestão de operações e Logística: Gerenciando Relacionamentos Colaborativos com Fornecedores, 2004.

DIAS, Marco Aurélio P., Administração de materiais: Uma abordagem logística, São Paulo: Atlas S.A., 1993.

DIAS, Marco Aurélio P. Administração de materiais: Uma abordagem logística, São Paulo: Atlas S.A., 1993.

DRUCKER, P. F., Innovation and entrepreneurship. Nova York: Harper Business, 2003, Inovação e espírito empreendedor, São Paulo: Pioneira Thomson. 1985.

FILHO, Gilberto Cavalcante de Albuquerque. Piscicultura Continental, Belo Horizonte, 1977.

FORD, D. et al. Managing Business Relationships. Chichester: Wiley, 2003. 
FRANCISCHINI, Paulino G.; GURGEL, Floriano do Amaral. Administração de materiais e do patrimônio. Thomson Pioneira, 2002.

FRIMAN, M.; GÄRLING, T.; MILLET, B.; MATTSSON, J.; JOHNSTON, R. An analysis of international business-to-business relationships based on the commitmenttrust theory. Industrial Marketing Management, v. 31, n. 5, 2002, p. 403-409.

GITOMER, Jeffrey. Livro de Vendas: princípios de excelência em vendas. São Paulo: Makron Books, 2006.

HEIDE, J. B.; JOHN, G. Do norms matter in marketing relationships? Journal of Marketing, v. 56, n. 2, p. 32-44, 1992.

KOTLER, Philip; ARMSTRONG, Gary. Princípios de Marketing - São Paulo: Prentice Hall, 2004.

KOTLER, Philip; HAIDER, Donal; REIN, Irving. Marketink Público. Ed MaKron Books, 1994.

KOTLER, Philip. Administração de Marketing. 10 ed. São Paulo: Prentice Hall, 2000.

LAS CASAS, Alexandre Luzzi. Administração de Vendas. São Paulo: Atlas, 2005.

LAS CASAS, Alexandre Luzzi. Administração de marketing: conceitos, planejamento e aplicações à realidade brasileira. São Paulo: Atlas, 2006.

LEE, D.; PAE, J.; WONG, Y. A model of close business relationships in China (guanxi). European Journal of Marketing, v. 35, n. 1/2, 2001, p. 51-69.

LUSCH, R. F.; BROWN, J. R. Interdependency, contracting, and relational behavior in market channels. Journal of Marketing, v. 60, n. 4, p. 19-38, 1996. 
MASO, Luciano. Marketing de Relacionamento: o que é? Pare que serve? Qual sua importância para o cliente? . RACl revista de administração e ciências contábeis do IDEAU. ISSN 1809-6212 Vol. 5 - n.10 - Janeiro - Junho 2010 - Semestral.

MCKENNA, Regis. Acesso Total. Rio de Janeiro: Elsevier, 2002.

OSTRENSKY, Antônio; BOEGER, Walter A. Piscicultura: Fundamentos e Técnicas de Manejo Livraria e editora agropecuária, 1998.

POZO, Amilton. Administração de recursos materiais e patrimoniais: Uma abordagem logística, 6ª edição, São Paulo (SP): Atlas, 2010.

PETER, J. Paul; DONNELLY JR, James H. Introdução ao marketing: criando valor para o cliente, Editora Saraiva, 2013.

SCHMITT, Bernd H. Gestão da experiência do cliente: uma revolução no relacionamento com os consumidores. Porto Alegre: Bookman, 2004.

SEVERINO, Antônio Joaquim. Metodologia do Trabalho Científico, Editora Cortez, 2012.

SLACK, Nigel. Administração da produção. 2. ed. São Paulo: Atlas, 2002.

SLONGO, Luiz Antônio; LIBERALI, Guilherme. Marketing de relacionamento: Estudos, cases e proposições de pesquisa. São Paulo: Atlas, 2004.

ZAND, D. E. Trust and managerial problem solving. Administrative Science Quarterly, v. 17, n. 2, p. 229-239, 1972.

Enviado: Setembro, 2019.

Aprovado: Maio, 2020. 